\title{
Produtividade e eficiência econômica de sistemas de produção de cria, recria e engorda de bovinos de corte na região sul do estado da Bahia
}

[Economic efficiency and productivity of life-cycle beef cattle production systems in the South of Bahia]

\author{
F.A. Barbosa ${ }^{1}$, D.S. Graça ${ }^{2}$, V.J. Andrade ${ }^{2}$, I.M. Cezar $^{3}$, G.G. Santos ${ }^{4}$, R.C. Souza ${ }^{4}$ \\ ${ }^{1}$ Universidade de Brasília - Brasília, DF \\ ${ }^{2}$ Escola de Veterinária - UFMG - Belo Horizonte, MG \\ ${ }^{3}$ UNIDERP/Anhanguera - Campo Grande, MS \\ ${ }^{4}$ Aluno de pós-graduação - EV-UFMG - Belo Horizonte, MG
}

\begin{abstract}
RESUMO
Estudaram-se a produtividade e a eficiência econômica de quatro sistemas de bovinos de corte, por meio de simulação, que diferiram quanto à taxa de natalidade (TN). A pesquisa foi realizada em uma fazenda de ciclo completo (SCC) com TN de $87 \%$, e mais três sistemas simulados: $-4 \mathrm{TN}$ com TN de $83 \%$; $-2 \mathrm{TN}$ com TN de $85 \%$; e $+2 \mathrm{TN}$ com TN de $89 \%$. O SCC foi baseado em dados de um sistema de cria, recria e engorda com média de 3.453 cabeças, localizado no sul da Bahia, no período de janeiro de 2000 a dezembro de 2002. As TN foram ajustadas à demanda energética dos animais em cada sistema e à evolução do rebanho durante três anos. A quantidade de carne vendida foi de 149, 146, 144, $141 \mathrm{~kg} / \mathrm{ha} / \mathrm{ano}$ para $-4 \mathrm{TN},-2 \mathrm{TN}$, SCC e +2TN, respectivamente. O lucro total acumulado, na mesma ordem de citação, foi de $\mathrm{R} \$ 780.695,42$; $\mathrm{R} \$ 737.526,16$; $\mathrm{R} \$ 727.031,52$ e $\mathrm{R} \$ 703.907,58$. O retorno do capital investido acumulado foi de 7,8; 7,4; 7,3 e 7,0\% para -4 TN, -2TN, SCC e +2TN, respectivamente. A variação da TN na atividade de cria, recria e engorda de bovinos alterou a produtividade e a eficiência econômica dos sistemas simulados. As respostas em produtividade e eficiência econômica diminuíram com o aumento da taxa de natalidade.
\end{abstract}

Palavras-chave: gado de corte, custo, lucro, rentabilidade, simulação

\begin{abstract}
Economic efficiency and productivity of life-cycle cattle raising systems were studied by simulations that differed in calving rates (CR). The study was conducted on a life-cycle cattle production system (SCC) with $87 \% C R$, and three simulated systems: $-4 C R$ with $83 \% C R$, $-2 C R$ with $85 \% C R$, and $+2 C R$ with $89 \%$ CR. The SCC was based on data from a life-cycle cattle system of 3,453 animals in the South of Bahia State, from January 2000 to December 2002. CR was adjusted according to energy requirement and herd composition in SCC during three years. Meat amount sold was 149, 146, 144, and 141kg/ha/year for $-4 C R,-2 C R, S C C$, and $+2 C R$, respectively. Accumulated profit and return on invested capital were $R \$ 780,695.42$ and $7.8 \% ; R \$$ $737,526.16$ and $7.4 \%$; $R \$ 727,031.52$ and 7.3\%; and $R \$ 703,907.58$ and $7.0 \%$ for $-4 C R,-2 C R$, SCC, and $+2 C R$, respectively. Calving rate variation modified the economic efficiency and productivity of simulated production systems. Economic efficiency and productivity results decreased as calving rate increased.
\end{abstract}

Keywords: beef cattle, cost, profit, profitability, simulation

\section{INTRODUÇÃO}

A simulação é uma técnica que envolve a elaboração de um modelo a partir de uma situação real (sistema) e posteriormente a realização de experimentos sobre esse modelo. É, portanto, uma metodologia para experimentação e predição (Wallhaus, 1969). Segundo Gastal
(1980), a simulação constitui instrumental de grande valor para a obtenção de resultados mais rápidos e, geralmente, com expressiva redução de custos, apesar da necessidade de pessoal especializado.

Nem sempre é possível estimar com precisão os efeitos de tomadas de decisões gerenciais e

Recebido em 11 de novembro de 2009

Aceito em 10 de junho de 2010

E-mail: fabianoalvim@unb.br 
tecnológicas, considerando possíveis interações entre componentes biológicos e econômicos associados às variações de clima e preço. Para minimizar riscos e erros e maximizar o lucro, é necessário que o administrador disponha de informações analíticas sobre os efeitos de possíveis escolhas no sistema de produção como um todo, do ponto de vista biológico e econômico. Dessa forma, os softwares são desenvolvidos de modo a constituírem importantes ferramentas analíticas para tomadas de decisões gerenciais e tecnológicas para sistemas da produção de pecuária, embora reconhecendo a simulação como abstração da realidade (Cezar e Alves, 1997).

O aumento da eficiência produtiva é primordial para a lucratividade da pecuária de corte, sendo que as atividades produtivas devem ser entendidas e manejadas dentro de um enfoque sistêmico, em busca da maximização de lucros. Os sistemas de produção de gado de corte são complexos e diversificados, não havendo fórmulas e nem recomendações únicas que possam ser largamente aplicadas por todo o Brasil. Portanto, cada produtor deve desenvolver seu sistema de produção, combinando suas metas às condições ambientais e mercadológicas (Hembry, 1991, citado por Abreu et al., 2003), aliado às capacidades financeiras e aos recursos humanos, com responsabilidade social e ambiental.

Beretta et al. (2001) mostraram em estudo de simulação que a redução da idade ao parto da matriz para dois anos aumentou a produtividade do sistema. Esse aumento da produção é dependente da taxa de natalidade que deve ser no mínimo de $70 \%$. Além disso, os indicadores técnicos e econômicos diferem de acordo com os sistemas de produção (cria ou ciclo completo). No sistema exclusivo de cria, a venda de vaca descarte tem grande contribuição na receita total do sistema; no ciclo completo, ocorre maior participação dos machos de engorda, que é um produto mais valorizado que a vaca descarte (Beretta et al., 2002). Além do preço de venda mais elevado do boi gordo, as categorias de recria e engorda são mais eficientes em ganho de peso do que as vacas.

O objetivo deste trabalho foi avaliar técnica e economicamente, por intermédio de simulação, a influência da alteração na taxa de natalidade em sistemas de produção de cria, recria e engorda (ciclo completo) de bovinos de corte no sul da Bahia.

\section{MATERIAL E MÉTODOS}

Avaliaram-se a produtividade e a eficência econômica de quatro sistemas de produção de ciclo completo de bovinos de corte, mediante simulação computacional. Os sistemas diferiram quanto à taxa de natalidade (TN). A pesquisa foi realizada em uma fazenda de ciclo completo (SCC) com TN de $87 \%$, e mais três sistemas simulados: $-4 \mathrm{TN}$ com TN de $83 \%$; $-2 \mathrm{TN}$ com TN de $85 \%$ e $+2 \mathrm{TN}$ com TN de $89 \%$. A simulação foi baseada na mudança de dois pontos percentuais da TN para cada sistema, sendo que a TN do +2TN é um índice elevado para a realidade da pecuária bovina de corte brasileira, não justificando aumentá-la.

Foi utilizado o estudo de casos (Yin, 1984; Alencar, 2004) com a pesquisa fundamentada em uma abordagem de análise quantitativa. Com o uso das planilhas eletrônicas (Microsoft Excel ${ }^{\circledR}$ ), foi possível avaliar, por intermédio da simulação, as alterações das taxas de natalidade, com base nos dados zootécnicos e econômicos acumulados do SCC, e verificar as variações de eficiência técnica e econômica decorrentes de mudanças no sistema de produção.

A fazenda, no sul da Bahia, adotava o sistema de ciclo completo (SCC): cria, recria e engorda de bovino, em 2.926ha, no município de Lajedão, na Bahia. O período analisado foi de janeiro de 2000 a dezembro de 2002. A propriedade era constituída de pastagens de Brachiaria brizantha cv. Marandu, Brachiaria decumbens cv. Basilisk e Brachiaria humidicula. As áreas dos módulos do rotacionado foram de 114 ha e mais cinco áreas de 80ha, totalizando 514ha. Essas áreas receberam calcário dolomítico e adubos químicos (nitrogênio, fósforo e potássio) somente na implantação das pastagens. Os bovinos recebiam suplemento mineral durante a época das águas com formulação específica para cada categoria. Na época da seca, os machos de engorda consumiam suplemento proteicomineral com ingestão média diária de $0,2 \%$ do peso vivo; as fêmeas de recria de cruzamento industrial para reposição recebiam suplemento proteico-mineral com ingestão média diária de $0,15 \%$ do peso vivo. As outras categorias de 
recria consumiam suplemento proteico-mineral com ingestão média diária de $0,1 \%$ do peso vivo. Os animais eram criados, exclusivamente, em sistema de pastagem. Foram vacinados contra febre aftosa, raiva, clostridiose e brucelose (fêmeas) e receberam vermífugo de amplo espectro. Todos os animais foram pesados à desmama e na saída da fazenda. O controle de moscas e carrapatos foi realizado conforme a infestação.

A composição racial do rebanho era à base da raça Tabapuã e um composto Bos taurus x Bos indicus. A maioria das matrizes zebuínas eram inseminadas com sêmen de touros Limousin e Red Angus, e as fêmeas resultantes desse cruzamento (F1) eram inseminadas com touros Santa Gertrudis, e, posteriormente, Senepol, formando um composto de três raças, mantendo, assim, um rebanho composto Bos taurus x Bos indicus. Outras matrizes zebuínas eram inseminadas com touros Tabapuã para a preservação da base genética zebuína e para a venda de tourinhos PO. O período da estação de monta era de 120 dias, em média, começando em novembro e terminando em março, com algumas variações em função da ocorrência de seca prolongada ou veranicos que poderiam afetar a qualidade e a disponibilidade de forrageira.

A mão de obra era formada por 17 empregados, um gerente administrativo, um gerente técnico, 13 vaqueiros, um auxiliar de serviços gerais e uma cozinheira.

Os indicadores zootécnicos utilizados para os sistemas foram: números de animais vendidos em função das categorias alteradas com a variação da taxa de natalidade, número médio de animais, taxa de lotação (cabeça/ha), kg de peso vivo vendido/ha, $\mathrm{kg}$ de peso vivo vendido total, taxa de natalidade e taxa de mortalidade à desmama.

A estrutura inicial do rebanho foi utilizada com base nos índices de natalidade, mortalidade, taxa de lotação, vendas e compras do SCC, acumulados, com início em janeiro de 2000. A evolução do rebanho, durante os três anos simulados, foi ajustada mantendo a mesma demanda energética e taxa de lotação do sistema conforme a variação da TN. A exigência energética para cada categoria animal alterada com a TN do rebanho foi estimada com base no NRC (Nutrient ..., 1996) (Tab. 1), em função da raça Santa Gertrudis - a de maior participação dos animais de cruzamento no rebanho total -, das diferentes categorias - bezerros, novilhas, novilhos e vacas - e estádio fisiológico prenhez, em lactação ou em crescimento, conforme os dados zootécnicos encontrados no SCC.

Os custos operacionais fixo, variável, total e o custo total foram representados pelos dados acumulados no período avaliado do SCC. As alterações dos custos com a alimentação, vacinas e medicamentos foram calculadas em função da variação do número médio de cabeças em cada sistema. Os outros custos operacionais variáveis e fixos foram mantidos constantes para os três sistemas. O custo de oportunidade variou de acordo com o desembolso e o valor patrimonial do rebanho em função da TN e o número médio de cabeças em cada sistema.

Tabela 1. Variação das exigências de energia líquida (Mcal) para bovinos de corte, da raça Santa Gertrudis, de acordo com as categorias

\begin{tabular}{lc}
\hline Categoria & Energia líquida (Mcal/dia) \\
\hline Vacas & 7,22 a 13,55 \\
Bezerros & 5,08 a 6,67 \\
Bezerras & 4,74 a 5,42 \\
Novilhos & 6,94 a 9,26 \\
Novilhas & 7,05 a 12,51 \\
\hline
\end{tabular}

Fonte: Nutrient ..., 1996.

As receitas dos sistemas foram caracterizadas pelo preço de venda (cabeça ou $\mathrm{kg}$ ) multiplicado pela quantidade de animais ou peso vendido de recria e engorda (machos e fêmeas), bem como pela venda de touros e vacas descartadas de cada sistema. Foi calculado o valor do estoque de animais em cada ano, multiplicando o número de cabeças pelo valor de mercado (no mês janeiro 
de todos os anos): o resultado dessa variação de estoque, positiva ou negativa, foi acrescentado à receita total daquele ano.

A avaliação da viabilidade econômica foi baseada na metodologia proposta por Frank (1978) e utilizada por Costa et al. (1986), Corrêa et al. (2000) e Guimarães et al. (2005). Para isso, foram utilizados os seguintes indicadores lucro operacional ou margem líquida (receita total custo operacional total) e lucro total (receita total - custo total). Para o cálculo dos juros (custo de oportunidade), foi utilizada a metodologia de valores decrescentes, em que as taxas de juros são maiores para o capital circulante do que para o capital fundiário e intermediárias para o capital de exploração fixo, sendo que a taxa de juros máxima a ser adotada foi de $6,75 \%$ ao ano, semelhante aos juros para financiamentos agropecuários (Tab. 2).

Foi utilizado o retorno do capital investido como parâmetro de avaliação de investimento, assim definido: retorno do capital investido $(\mathrm{RCI})=$ proporção obtida pelos resultados gerados anualmente na atividade, apurada pela expressão: retorno do capital investido $=$ lucro $\div$ capital investido na atividade. O RCI foi avaliado calculando o lucro operacional total (sem o custo de oportunidade) e o lucro total (com o custo de oportunidade). Ao avaliar o RCI pelo lucro total, foram realizadas duas análises: uma considerou a variação patrimonial (positiva ou negativa) adicionada como um resultado econômico, a outra não considerou a variação patrimonial no resultado econômico.

Tabela 2. Diferentes tipos de juros de acordo com os itens específicos do custo da criação de bovinos de corte

\begin{tabular}{lc}
\hline Item & Taxa de juros anual (\%) \\
\hline Terra & 3,00 \\
Benfeitorias & 3,60 \\
Animais de produção & 4,80 \\
Animais - recria e engorda & 6,75 \\
Máquinas e equipamentos & 4,80 \\
Insumos & 6,75 \\
Mão de obra & 6,75 \\
Reparo e manutenção & 6,75 \\
\hline
\end{tabular}

Fonte: Adaptado de Guimarães, 2003.

O valor patrimonial foi calculado em função do total de bens, a cada ano, multiplicado pelo valor de mercado segundo Nogueira (2004). Foram utilizados os preços das terras, a arroba de boi gordo, de vaca, os preços de bezerros (as), novilhas (os) e garrotes com base nos preços do Instituto FNP (Anualpec, 2002, 2003, 2004). Os valores das benfeitorias, das máquinas e dos equipamentos foram somados aos investimentos realizados a cada ano e subtraídos dos valores das depreciações. A variação patrimonial foi calculada pelo resultado do valor do patrimônio (terras e pastagens, animais, benfeitorias e máquinas) no ano subsequente em relação ao ano estudado.

Foram calculados outros indicadores econômicos dos sistemas estudados: custo por cabeça $(\mathrm{R} \$)=$ custo obtido dividido pelo número médio de cabeças no período; lucro operacional/hectare $(\mathrm{R} \$)$ = lucro operacional obtido dividido pelo total de hectares utilizados na atividade; lucro total/hectare $(\mathrm{R} \$)$ = lucro total obtido dividido pelo total de hectares utilizados na atividade.

\section{RESULTADOS E DISCUSSÃO}

A variação na TN alterou a quantidade de cabeças totais, o número de bezerros desmamados e a quantidade de $\mathrm{kg}$ de peso vivo vendido em cada sistema (Tab. 3). A diminuição na TN aumentou o descarte de vacas vazias e diminuiu o número de bezerros desmamados por ano. O descarte de vacas vazias foi de 61 e 31 cabeças/ano para $-4 \mathrm{TN}$ e $-2 \mathrm{TN}$, respectivamente, e a diminuição de bezerros desmamados foi de 57 e 28 cabeças/ano, na mesma ordem de citação. Para manter a lotação e a demanda energética no sistema $-4 \mathrm{TN}$, foram retidos, anualmente, 90 novilhos (até um ano de idade), para posterior abate aos 26 meses de idade, conforme evolução do rebanho, além da compra de 40 bezerros desmamados, no ano de 2001, e abate em novembro de 2002. Para manter a 
lotação e a demanda energética no sistema $-2 \mathrm{TN}$, foram retidos 45, 64 e 64 novilhos (até um ano de idade), nos anos 2000, 2001 e 2002, respectivamente, para posterior abate aos 26 meses de idade, conforme evolução do rebanho. $\mathrm{O}$ aumento na TN no $+2 \mathrm{TN}$ resultou no acréscimo de mais 29 vacas paridas/ano, com maior número de bezerros desmamados e diminuição do descarte de vacas vazias. Para manter a lotação e a demanda energética no sistema $+2 \mathrm{TN}$, foram retidas 15 novilhas (até um ano de idade) e vendidos 14 animais desmamados e 15 novilhas para abate, até dois anos de idade, conforme evolução do rebanho.

Os valores do peso médio vendido foram de 149, 146,144 e $141 \mathrm{~kg} / \mathrm{ha} /$ ano para $-4 \mathrm{TN},-2 \mathrm{TN}, \mathrm{SCC}$ e $+2 \mathrm{TN}$, respectivamente (Tab. 3). Beretta et al. (2001, 2002) encontraram valores máximos de $\mathrm{kg}$ de peso vivo produzido/ha próximos em sistemas completo e de cria, 151 e $160 \mathrm{~kg} / \mathrm{ha} / \mathrm{ano}$, respectivamente, em uma área de 1.000 hectares, também em estudo de simulação. Os sistemas mais produtivos foram os que apresentavam menor idade ao parto das novilhas (dois anos) e de abate dos machos (24 meses). As taxas de natalidade responderam de forma quadrática em função da produtividade ( $\mathrm{kg}$ peso vivo $(\mathrm{PV}) / \mathrm{ha}$ de pastejo), que foi influenciada pela redução da idade ao parto e ao abate dos machos, e pelo sistema de produção (Beretta et al., 2001, 2002). Ítavo et al. (2008) encontraram valores médios de $1.505 \mathrm{~kg}$ de peso vivo produzido/ha na recria e engorda de novilhos Canchim-Nelore em pastagens de Brachiaria decumbens, com taxa de lotação média de 3,22 UA/ha, e que receberam $0,7 \%$ do peso corporal de suplemento proteicoenergético. Esses resultados demonstram que o sistema de recria e engorda pode ser mais produtivo que o sistema de ciclo completo, principalmente quando a taxa de lotação é mais elevada.

Tabela 3. Média de animais no rebanho e dos índices zootécnicos nos diferentes sistemas simulados nos anos de 2000 a 2002

\begin{tabular}{lcccc}
\hline & $-4 \mathrm{TN}$ & $-2 \mathrm{TN}$ & $\mathrm{SCC}$ & $+2 \mathrm{TN}$ \\
\hline Cabeças totais & 3.775 & 3.777 & 3.792 & 3.802 \\
Matrizes - cabeças & 1.510 & 1.510 & 1.510 & 1.510 \\
Natalidade - cabeças & 1.253 & 1.283 & 1.314 & 1.343 \\
Desmama - cabeças & 1.215 & 1.244 & 1.272 & 1.302 \\
kg peso vivo total vendido & 1.307 .647 & 1.283 .361 & 1.261 .659 & 1.237 .296 \\
kg peso vivo total vendido/ha/ano & 149 & 146 & 144 & 141 \\
Taxa de natalidade - (TN) - \% & 82,97 & 84,97 & 86,97 & 88,97 \\
Taxa mortalidade até desmama - \% & 3,06 & 3,06 & 3,06 & 3,06 \\
Cabeças/hectare & 1,24 & 1,24 & 1,24 & 1,24 \\
\hline
\end{tabular}

TN: taxa de natalidade; SCC: sistema de ciclo completo com TN de 87\%; -4TN: sistema de ciclo completo com TN de 83\%; -2TN: sistema de ciclo completo com TN de 85\%; +2TN: sistema de ciclo completo com TN de $89 \%$.

A composição do rebanho no final do período simulado variou de acordo com cada sistema (Tab. 4). Ocorreu aumento do rebanho nos quatros sistemas, pois o SCC (base da simulação) variou dessa maneira no decorrer do período avaliado. Esse aumento está relacionado à maior disponibilidade de forragem decorrente das novas áreas de pastagens formadas, nos anos de 2000 e 2001, aliado ao manejo de rotação de animais nas pastagens, contribuindo para um maior suporte total das propriedades. Os sistemas $-4 \mathrm{TN},-2 \mathrm{TN}$ e $+2 \mathrm{TN}$ apresentaram variação na produção de bezerros em função da TN. O número de vacas, novilhas e novilhos variou em cada sistema em função das vendas e da retenção desses animais, como mencionado anteriormente. Abreu et al. (2003) também observaram maior produção de bezerros em razão da mudança da taxa de natalidade de 65 para $75 \%$, sendo que esse aumento no número de vacas e de bezerros foi gradativo em função dos quatro primeiros anos simulados, conforme encontrado neste estudo. Beretta et al. (2002) também encontraram menor proporção de novilhas de reposição com o aumento da taxa de natalidade de 50 para $80 \%$, com a idade ao primeiro parto das matrizes aos 36 meses de idade. Esse fato ocorre pela necessidade de descartar a novilha para futura reposição com a retenção da matriz prenha como encontrado no $+2 \mathrm{TN}$. 
Tabela 4. Composição do rebanho de acordo com o início (janeiro/2000) e final do período avaliado (dezembro/ 2002) nos sistemas simulados

\begin{tabular}{lccccc} 
& $\begin{array}{c}\text { Todos } \\
\text { sistemas* }\end{array}$ & $-4 T N$ & $-2 T N$ & SCC & +2 TN \\
\hline & Jan/2000 & Dez/2002 & Dez/2002 & Dez/2002 & Dez/2002 \\
\hline Categoria & & & & & \\
\hline Vacas & 1.129 & 1.761 & 1.761 & 1.761 & 1.761 \\
Bezerras - 0 a 12 meses & 272 & 740 & 749 & 763 & 777 \\
Bezerros - 0 a 12 meses & 293 & 765 & 775 & 789 & 804 \\
Novilhas - 12 a 24 meses & 540 & 538 & 577 & 622 & 607 \\
Novilhos - 12 a 24 meses & 416 & 319 & 303 & 253 & 253 \\
Novilhas - 24 a 36 meses & 2 & 62 & 62 & 62 & 62 \\
Touros & 0 & 3 & 3 & 3 & 3 \\
\hline TOTAL & 2.652 & 4188 & 4.230 & 4.253 & 4.267 \\
\hline
\end{tabular}

*O rebanho inicial é o mesmo para todos os sistemas. TN: taxa de natalidade; SCC: sistema de ciclo completo com TN de 87\%; -4TN: sistema de ciclo completo com TN de 83\%; -2TN: sistema de ciclo completo com TN de $85 \%$; +2TN: sistema de ciclo completo com TN de $89 \%$.

Beretta et al. (2002), em estudos de simulação de um sistema de ciclo completo de bovinos de corte estabilizado, encontraram resposta quadrática da TN em função da produtividade ( $\mathrm{kg}$ de peso vivo/hectare de pastejo), da idade ao primeiro parto das fêmeas e ao abate dos machos. A maior produtividade foi verificada com TN entre 70 e $80 \%$, para a idade ao primeiro parto das fêmeas aos dois anos. Nas simulações do sistema SCC, ocorreu variação no kg de peso vendido em função da TN. Houve aumento de peso com a diminuição da TN (Tab. 3), em razão da maior quantidade de venda de matrizes para o abate e de novilhos de engorda comparada à de bezerros e novilhas (Tab. 5). A maior quantidade vendida de bezerros e novilhas no $+2 \mathrm{TN}$ não foi suficiente para compensar a queda nas vendas das vacas descartes com o aumento da TN (Tab. 6). O impacto da mudança introduzida na fase de cria foi menor quando se avaliou o sistema do ciclo completo de produção, no qual a resposta produtiva (kg PV/ha) à melhora dos coeficientes reprodutivos está condicionada à idade ao abate dos novilhos (Beretta et al., 2002).

Tabela 5. Número de cabeças (cab.) e kg total nos diferentes sistemas em função da categoria alterada com a variação da taxa de natalidade nos anos de 2000 a 2002

\begin{tabular}{lcccccccc}
\hline & \multicolumn{2}{c}{$-4 \mathrm{TN}$} & \multicolumn{2}{c}{$-2 \mathrm{TN}$} & \multicolumn{2}{c}{ SCC } & \multicolumn{2}{c}{$+2 \mathrm{TN}$} \\
\hline Vendas & $\mathrm{cab}$. & $\mathrm{kg}$ Total & $\mathrm{cab}$. & $\mathrm{kg}$ Total & $\mathrm{cab}$. & $\mathrm{kg}$ Total & $\mathrm{cab}$. & $\mathrm{kg}$ Total \\
\hline $\begin{array}{l}\text { Bezerros } \\
\text { desmamados }\end{array}$ & 426 & 105.469 & 523 & 127.137 & 696 & 166.596 & 738 & 175.775 \\
$\begin{array}{l}\text { Novilhas }-2 \\
\text { anos }\end{array}$ & 405 & 113.379 & 495 & 141.220 & 588 & 167.916 & 618 & 178.545 \\
$\begin{array}{l}\text { Novilhos }-2 \\
\text { anos }\end{array}$ & 1365 & 608.476 & 1.264 & 563.945 & 1.169 & 522.035 & 1.169 & 522.035 \\
$\begin{array}{l}\text { Vacas } \\
\text { descartes }\end{array}$ & 580 & 270.365 & 490 & 241.100 & 397 & 195.153 & 310 & 152.174 \\
\hline Total & 2.776 & 1.097 .688 & 2.772 & 1.073 .402 & 2.850 & 1.051 .700 & 2.835 & 1.028 .529 \\
\hline $\begin{array}{l}\text { Diferença } \\
\text { para SCC }\end{array}$ & & 45.988 & & 21.702 & & & & $(23.171)$ \\
\hline
\end{tabular}

${ }^{1}$ Valores numéricos entre parênteses são negativos. TN: taxa de natalidade; SCC: sistema de ciclo completo com TN de $87 \%$; -4TN: sistema de ciclo completo com TN de $83 \%$; -2TN: sistema de ciclo completo com TN de $85 \%$; $+2 \mathrm{TN}$ : sistema de ciclo completo com TN de $89 \%$. 
Tabela 6. Receita acumulada nos diferentes sistemas em função das categorias alteradas com a variação da taxa de natalidade nos anos de 2000 a 2002

\begin{tabular}{lcccc} 
& $-4 T N$ & $-2 T N$ & SCC & $+2 T N$ \\
\hline Venda & R\$ Total & R\$ Total & R\$ Total & R\$ Total \\
\hline Bezerros desmamados & $203.903,25$ & $247.987,92$ & $328.942,03$ & $347.016,24$ \\
Novilhas -2 anos & $163.708,37$ & $200.475,98$ & $236.896,68$ & $251.340,04$ \\
Novilhos -2 anos & $914.556,23$ & $846.132,23$ & $781.900,32$ & $781.900,32$ \\
Vacas descartes & $381.263,32$ & $322.417,30$ & $261.606,31$ & $204.726,06$ \\
\hline Total & $1.663 .431,17$ & $1.617 .013,43$ & $1.609 .345,34$ & $1.584 .982,66$ \\
\hline Diferença para SCC & $54.085,83$ & $7.668,09$ & & $(24.362,67)$
\end{tabular}

1- Valores numéricos entre parênteses são negativos. TN: taxa de natalidade; SCC: sistema de ciclo ompleto com TN de $87 \%$; -4TN: sistema de ciclo completo com TN de $83 \%$; -2TN: sistema de ciclo completo com TN de $85 \%$; $+2 \mathrm{TN}$ : sistema de ciclo completo com TN de $89 \%$.

O custo total $(\mathrm{CT})$ médio por cabeça foi maior para os sistemas com menor número de cabeças, $-4 \mathrm{TN}$ e $-2 \mathrm{TN}$, pois os custos fixos e de oportunidade (terras e pastagens, benfeitorias e máquinas) permaneceram constantes e o custo unitário total aumentou com essa diminuição de rebanho. A receita total média por cabeça foi maior para o sistema $-4 \mathrm{TN}$ em razão da maior receita total. Essa maior receita total por cabeça no -4TN proporcionou maior lucro do que nos sistemas -2TN, SCC e +2TN (Tab. 7).

Tabela 7. Custos e indicadores econômicos dos sistemas (R \$/cabeça/ano) nos anos de 2000 a 2002

\begin{tabular}{lcccc}
\hline Indicador & $-4 \mathrm{TN}$ & $-2 \mathrm{TN}$ & $\mathrm{SCC}$ & $+2 \mathrm{TN}$ \\
\hline Custo operacional variável - R\$/cabeça/ano & 92,05 & 90,45 & 90,21 & 90,06 \\
Custo operacional fixo - R\$/cabeça/ano & 77,79 & 77,75 & 77,44 & 77,24 \\
Custo operacional total - R\$/cabeça/ano & 169,84 & 168,20 & 167,66 & 167,30 \\
Receita total - R\$/cabeça/ano & 303,72 & 297,95 & 295,95 & 293,25 \\
Lucro operacional - R\$/cabeça/ano & 133,88 & 129,76 & 128,29 & 125,95 \\
Custo de oportunidade- R\$/cabeça/ano & 64,95 & 64,76 & 64,38 & 64,24 \\
Custo total - R \$/cabeça/ano & 234,79 & 232,86 & 232,04 & 231,54 \\
Lucro total - R\$/cabeça/ano & 68,94 & 65,09 & 63,91 & 61,71 \\
Média anual de cabeças & 3.775 & 3.777 & 3.792 & 3.802 \\
\hline
\end{tabular}

Lucro operacional = margem líquida. TN: taxa de natalidade; SCC: sistema de ciclo completo com TN de 87\%; 4TN: sistema de ciclo completo com TN de $83 \%$; $-2 \mathrm{TN}$ :- sistema de ciclo completo com TN de $85 \%$; $+2 \mathrm{TN}$ : sistema de ciclo completo com TN de $89 \%$.

As receitas totais acumuladas nos quatro sistemas pagaram todos os custos e resultaram em lucros totais de $\mathrm{R} \$ 780.695,42$; $\mathrm{R} \$ 737.526,16 ; \quad \mathrm{R} \$ 727.031,52$ e $\mathrm{R} \$ 703.907,58$ para $-4 \mathrm{TN}$; $-2 \mathrm{TN}$; SCC e $+2 \mathrm{TN}$, respectivamente. $\mathrm{O}$ retorno do capital investido (RCI) acumulado, analisado pelo lucro total, foi de 7,79, 7,36, 7,26 e 7,03\%, na mesma ordem de citação (Tab. 8). Nessas situações, tem-se o lucro econômico com tendência de crescimento no negócio (Reis, 2002). O sistema $-4 \mathrm{TN}$ resultou no maior custo total acumulado em razão da compra de bezerros para recria e engorda, mas com maior receita total, levando ao maior RCI. Apesar da maior variação de rebanho do $+2 \mathrm{TN}$, a receita proveniente de vendas de bovinos foi menor que nos outros sistemas e, aliada ao maior custo total, fez com que o lucro total e o RCI fossem mais baixos que nos sistemas $-4 \mathrm{TN},-2 \mathrm{TN}$ e SCC.

Os lucros totais acumulados por hectare foram $\mathrm{R} \$ 266,81, \mathrm{R} \$ 252,06 ; \mathrm{R} \$ 248,47$ e $\mathrm{R} \$ 240,57$ para $-4 \mathrm{TN},-2 \mathrm{TN}, \mathrm{SCC}$ e $+2 \mathrm{TN}$, respectivamente (Tab. 8). No sistema de recria e engorda de novilhos Canchim-Nelore que receberam suplemento proteico-energético, em pastagens de 
Brachiaria decumbens, o lucro total médio por hectare foi de $\mathrm{R} \$ 288,66$ (Ítavo et al., 2008). Abreu et al. (2003) encontraram maior VPL e margem bruta por hectare ao avaliarem o efeito do aumento da taxa de natalidade de 65 para $75 \%$ em uma fazenda tradicional com 1.220 hectares de pastagens e 1.593 cabeças de raças zebuínas, no Pantanal. $\mathrm{O}$ aumento dos indicadores econômicos simulados por Abreu et al. (2003) foi diferente das respostas encontradas neste estudo, que não foram crescentes em função do aumento da TN. Essas diferenças podem estar relacionadas às taxas de natalidade avaliadas, às raças dos animais, à idade ao primeiro parto e ao abate, bem como ao ano e ao local avaliado.

Tabela 8. Custos e indicadores econômicos dos sistemas acumulados (R\$) nos anos de 2000 a 2002

\begin{tabular}{|c|c|c|c|c|}
\hline & $-4 \mathrm{TN}$ & $-2 \mathrm{TN}$ & SCC & $+2 \mathrm{TN}$ \\
\hline Indicador & $\begin{array}{l}\text { Acumulado - } \\
\text { R\$ } \\
\end{array}$ & $\begin{array}{c}\text { Acumulado - } \\
\text { R \$ }\end{array}$ & $\begin{array}{l}\text { Acumulado - } \\
\text { R\$ } \\
\end{array}$ & $\begin{array}{c}\text { Acumulado - } \\
\text { R\$ }\end{array}$ \\
\hline Custo operacional variável & $1.042 .446,38$ & $1.024 .849,86$ & $1.026 .261,42$ & $1.027 .244,48$ \\
\hline Custo operacional fixo & $880.996,33$ & $880.996,33$ & $880.996,33$ & $880.996,33$ \\
\hline Custo operacional total & $1.923 .442,72$ & $1.905 .846,19$ & $1.907 .257,75$ & $1.908 .240,82$ \\
\hline Receita total & $3.439 .673,95$ & $3.376 .108,01$ & $3.366 .684,92$ & $3.344 .857,24$ \\
\hline Lucro operacional $^{1}$ & $1.516 .231,23$ & $1.470 .261,81$ & $1.459 .427,16$ & $1.436 .616,42$ \\
\hline Lucro operacional/hectare & 518,19 & 502,48 & 498,78 & 481,36 \\
\hline Patrimônio & $7.706 .147,21$ & $7.716 .980,21$ & $7.715 .225,21$ & 7.717.760,21 \\
\hline Terras e pastagens & $4.764 .520,70$ & $4.764 .520,70$ & $4.764 .520,70$ & $4.764 .520,70$ \\
\hline Rebanho & $2.314 .256,80$ & $2.325 .089,80$ & $2.323 .334,80$ & $2.325 .869,80$ \\
\hline Benfeitorias & $528.532,29$ & $528.532,29$ & $528.532,29$ & $528.532,29$ \\
\hline Máquinas e equipamentos & $98.837,42$ & $98.837,42$ & $98.837,42$ & $98.837,42$ \\
\hline Retorno do capital investido (\%) & 16,32 & 15,84 & 15,72 & 15,47 \\
\hline Custo de oportunidade & $735.535,81$ & $732.735,65$ & $732.395,64$ & $732.708,84$ \\
\hline Terras e pastagens & $298.782,74$ & $298.782,74$ & $298.782,74$ & $298.782,74$ \\
\hline Rebanho & $309.159,60$ & $306.953,33$ & $306.565,67$ & $306.845,70$ \\
\hline Benfeitorias & $57.738,26$ & $57.738,26$ & $57.738,26$ & $57.738,26$ \\
\hline Máquinas e equipamentos & $16.435,21$ & $16.435,21$ & $16.435,21$ & $16.435,21$ \\
\hline Desembolsos & $53.419,99$ & $52.826,11$ & $52.873,75$ & $52.914,03$ \\
\hline Custo total & $2.658 .978,52$ & $2.638 .581,84$ & $2.639 .653,89$ & $2.640 .949,66$ \\
\hline Variação patrimonial & $2.644 .645,23$ & $2.655 .478,23$ & $2.653 .723,23$ & $2.656 .258,23$ \\
\hline Terras e pastagens & $1.371 .925,07$ & $1.371 .925,07$ & $1.371 .925,07$ & $1.371 .925,07$ \\
\hline Rebanho & $1.317 .174,25$ & $1.328 .007,25$ & $1.326 .252,25$ & $1.328 .787,25$ \\
\hline Benfeitorias & $(17.953,01)$ & $(17.953,01)$ & $(17.953,01)$ & $(17.953,01)$ \\
\hline Máquinas e equipamentos & $(26.501,08)$ & $(26.501,08)$ & $(26.501,08)$ & $(26.501,08)$ \\
\hline Lucro total & $780.695,42$ & $737.526,16$ & $727.031,52$ & $703.907,58$ \\
\hline Lucro total/hectare & 266,81 & 252,06 & 248,47 & 240,57 \\
\hline $\begin{array}{l}\text { Retorno do capital investido sem } \\
\text { variação patrimonial (\%) }\end{array}$ & 7,79 & 7,36 & 7,26 & 7,03 \\
\hline $\begin{array}{l}\text { Retorno do capital investido com } \\
\text { variação patrimonial (\%) }\end{array}$ & 36,12 & 35,81 & 35,68 & 33,54 \\
\hline
\end{tabular}

Valores numéricos entre parênteses são negativos. ${ }^{1}$ Lucro operacional = margem líquida. TN: taxa de natalidade; SCC: sistema de ciclo completo com TN de $87 \%$; -4TN: sistema de ciclo completo com TN de $83 \%$; $-2 \mathrm{TN}$ : sistema de ciclo completo com TN de $85 \%$; $+2 \mathrm{TN}$ : sistema de ciclo completo com TN de $89 \%$. 


\section{CONCLUSÕES}

A variação da taxa de natalidade na atividade de cria, recria e engorda de bovinos de corte alterou a produtividade e a eficiência econômica dos sistemas de produção simulados, sendo que essas respostas não foram crescentes com o aumento da taxa de natalidade. A atividade de cria, recria e engorda de bovinos, na região sul da Bahia, foi viável economicamente, considerando as taxas médias de natalidade de 83, 85, 87 e 89\%, durante os três anos simulados. $\mathrm{O}$ aumento da taxa de natalidade levou à diminuição de peso vivo vendido em razão da maior retenção de vacas prenhas no rebanho e a venda das novilhas que seriam a reposição dessas matrizes. A diminuição da taxa de natalidade levou ao aumento de peso vivo vendido em razão da maior venda de novilhos para abate e de vacas descartes.

\section{REFERÊNCIAS BIBLIOGRÁFICAS}

ABREU, U.G.P.; CEZAR, I.M.; TORRES, R.A. Análise bioeconômica da introdução de período de monta em sistemas de produção de rebanhos de cria na região do Brasil Central. Rev. Bras. Zootec., v.32, p.1198-1206, 2003.

ALENCAR, E. Metodologia científica e elaboração de monografia. Lavras: UFLA/FAEPE, 2004. 131p.

ANUALPEC. Anuário da Pecuária Brasileira. São Paulo: Instituto FNP, 2002. 400p.

ANUALPEC. Anuário da Pecuária Brasileira. São Paulo: Instituto FNP, 2003. 400p.

ANUALPEC. Anuário da Pecuária Brasileira. São Paulo: Instituto FNP, 2004. 476p.

BERETTA, V.; LOBATO, J.F.P.; MIELITZ NETTO, C.G. Produtividade e eficiência biológica de sistemas pecuários de cria diferindo na idade das novilhas ao primeiro parto e na taxa de natalidade do rebanho no Rio Grande do Sul. Rev. Bras. Zootec., v.30, p.12781286, 2001.

BERETTA, V.; LOBATO, J.F.P.; MIELITZ NETTO, C.G. Produtividade e eficiência biológica de sistemas de produção de gado de corte de ciclo completo no Rio Grande de Sul. Rev. Bras. Zootec., v.31, supl., p.9911001, 2002.

CEZAR, I.M.; ALVES, R.G.O. Embrapec: modelo bioeconômico de pecuária de corte. Campo Grande: Embrapa/CNPGC, 1997. (Manual do usuário).
CORRÊA, E.S.; VIEIRA, A.; COSTA, F.P. et al. Sistema semi-intensivo de produção de carne de bovinos nelores no Centro-Oeste do Brasil. Campo Grande: Embrapa/CNPGC, 2000. (Documento, 95).

COSTA, F.P.; PACHECO, J.A.C.; CORRÊA, E.S. et al. Estimativa do custo de produção da carne bovina para a região Centro-Oeste: setembro de 1986. Campo Grande: Embrapa/CNPGC, 1986. (Comunicado Técnico, 30).

FRANK, R.G. Introducción al cálculo de costos agropecuarios. Buenos Aires: El Ateneo, 1978.

GASTAL, E. Enfoque de sistemas na programação da pesquisa agropecuária. Brasília: IICA, 1980.

GUIMARÃES, P.H.S. Comparação econômica entre produção de fêmeas $F_{1}$ Holandês X Gir e alternativas de produção de gado de corte por meio de simulação. 2003. 48f. Dissertação (Mestrado) - Escola de Veterinária, Universidade Federal de Minas Gerais, Belo Horizonte.

GUIMARÃES, P.H.S; MADALENA, F.E.; CEZAR, I.M. Simulação dos efeitos dos preços de produtos na avaliação econômica de três sistemas alternativos de bovinocultura de cria. Arq. Bras. Med. Vet. Zootec., v.57, supl.2, p.227-230, 2005.

ÍTAVO, L.C.V.; DIAS, A.M.; ÍTAVO, C.C.B.F. Desempenho produtivo, características de carcaça e avaliação econômica de bovinos cruzados, castrados e não-castrados, terminados em pastagens de Brachiaria decumbens. Arq. Bras. Med. Vet. Zootec., v.60, p.1157-1165, 2008 .

NOGUEIRA, M.P. Gestão de custos e avaliação de resultados: agricultura e pecuária. Bebedouro: Scot Consultoria, 2004. 219p.

NUTRIENT requeriments of beef cattle. 7.ed. Washington: National Academy of Sciences, 1996. 242p.

REIS, R.P. Fundamentos de economia aplicada. Lavras: UFLA/FAEPE, 2002. 95p.

WALLHAUS, R.A. Modeling for higher education administration and management. In: JOHNSON, C.B.; KATZENMEYER, W.G. Management information systems in higher education: the state of the art. Durham: Duke University, 1969. p.125-144.

YIN, R.K. Case study research: design and methods. Beverly Hills, CA: Sage Publishing, 1984. 